\title{
Low dose magnesium sulphate regimen and maternal outcome of patients with eclampsia
}

\author{
Palvi Banotra* \\ Department of Health and Medical Education, Jammu and Kashmir Government, Jammu and Kashmir, India
}

Received: 29 December 2021

Accepted: 14 January 2022

\author{
*Correspondence: \\ Dr. Palvi Banotra, \\ E-mail: palvibntr@gmail.com
}

Copyright: $\odot$ the author(s), publisher and licensee Medip Academy. This is an open-access article distributed under the terms of the Creative Commons Attribution Non-Commercial License, which permits unrestricted non-commercial use, distribution, and reproduction in any medium, provided the original work is properly cited.

\begin{abstract}
Background: Preeclampsia, a serious pregnancy complication which is commonly characterized by high blood pressure, presence of protein in the urine and sometimes swelling in women's feet, legs and hands. With this condition, patient's high blood pressure often results in seizures. Generally, the outcome remains good, however, eclampsia can be life threatening and disastrous.

Methods: This cross-sectional study considered 114 patients who meet inclusion criteria and agreed to will-fully participate in the study were evaluated for different parameters. Patients who developed eclampsia during intra-natal and postnatal period were included in the study. The aim of the study was to evaluate the maternal outcome among all patients of eclampsia treated with low magnesium sulphate dosage therapy.

Results: The present study revealed, very low fit recurrence rate, low mortality rate, zero treatment failure rate, no toxicity and $(99.12 \%)$ success rate.

Conclusions: Apart from zero percent treatment failure rate, Low maternal mortality and fit recurrence rate encouraged us to continue the treatment with low dose $\mathrm{MGSO}_{4}$ regimen. Thus, low dose magnesium sulphate has been found very effective in treating the eclampsia and at the same time maintains the high safety margin.
\end{abstract}

Keywords: Preeclampsia, Eclampsia, Magnesium sulphate

\section{INTRODUCTION}

Preeclampsia, a serious pregnancy complication which is commonly characterized by high blood pressure, presence of protein in the urine and sometimes swelling in women's feet, legs and hands. Preeclampsia usually occurs after 20 weeks of pregnancy in women who had normal blood pressure, however, the possibility of developing preeclampsia earlier or just after delivery cannot be ruled out. Severity of preeclampsia can range from mild to severe.

Preeclampsia, if left untreated may invite serious health consequences for mothers as well as for babies. Sometimes preeclampsia may progress to a fatal condition which commonly known as eclampsia. With this condition, patient's high blood pressure often results in seizures.
Generally the outcome remains good, however, eclampsia can be life threatening and disastrous. It has been observed that around 10\%-15\% maternal deaths are associated with preeclampsia and eclampsia. ${ }^{1}$ Majority of maternal deaths are attributable to eclampsia rather than preeclampsia. Perinatal mortality is high following preeclampsia, and even higher following eclampsia.

It has been seen that public hospitals in low- and middleincome countries generally have a constrained access to intensive care unit, with the result mortality and associated morbidity escalates and remains on higher side in comparison to those countries where optimal hospital facilities are available. ${ }^{1}$ The only interventions shown to prevent preeclampsia are antiplatelet agents, primarily low dose aspirin, and calcium supplementation. Treatment is largely symptomatic. However, amongst the principles of 
management of eclampsia, the first and foremost is the control of convulsions. Numerous drugs and regimens have been exploited and recommended for management of eclampsia but among all anticonvulsant drugs used in the last 70 years, magnesium sulphate has received the maximum attention from a good corpus of scholars. Following publication of collaborative eclamptic trial, magnesium sulphate has been regarded as the predominant choice as it controls eclamptic convulsions and prevents recurrence of convulsion more effectively than diazepam and phenytoin. ${ }^{2,3}$

The credit for popularizing magnesium sulphate in the treatment of eclampsia goes to Pritchard. ${ }^{4} \mathrm{He}$ introduced a dose regime which is famously known as Pritchard regime that has remained a gold standard. ${ }^{5}$ Howbeit, in Indian women the average weight is less compared to western women and administering them with Pritchard regime might be fatal because of the possibility of respiratory depression. There has been a thread bearing discussion on the suitable dosage of magnesium sulphate for the treatment of eclampsia. Several comparative studies have been conducted on the low dosage of $\mathrm{MgSO}_{4}$ and the outcome has been mostly insignificant in comparison to standard regime with respect to several parameters including fit recurrence rate. The present study has been conducted to aim at evaluating the maternal outcome among all patients of eclampsia treated with low magnesium sulphate dosage therapy.

\section{METHODS}

The present study was conducted in the department of obstetrics and gynecology Lala Ded Hospital, Srinagar from March 2016 to February 2017. A total of 114 patients were included in the study who meet inclusion criteria and agreed to willfully participate in the study were evaluated for different parameters. Patients who developed eclampsia during intra-natal and postnatal period were included in the study. All the patients presenting with eclampsia were subjected to detailed history and clinical examination including general physical, obstetrical and systemic examination. Routine antenatal examination along with some additional lab investigations like KFT; LFT etc. was performed.

\section{Protocol for eclampsia}

\section{Loading dose}

$4 \mathrm{~g}$ magnesium sulphate was given intravenously, diluted in $20 \mathrm{cc}$ of $5 \%$ dextrose, slower over 15-20 min.

\section{Maintenance dose}

$2 \mathrm{~g}$ magnesium sulphate intravenously, similarly diluted was given 3 hourly till 24 hours after delivery or after last convulsion, whichever was later. For recurrence of convulsion: If convulsion occurred half-an-hour after the loading dose, then only it was taken as recurrence of convulsion and in that case an additional dose of $2 \mathrm{~g}$ intravenously was given and previous dose schedule of three hourly injection to be continued. Failure of treatment would mean uncontrolled convulsions even after 2 additional doses.

All the patients were monitored on clinical criteria. Before each dose of magnesium sulphate, toxicity in the form of deep tendon reflexes, urine output $(30 \mathrm{ml} / \mathrm{hr})$ and respiratory rate $(16 / \mathrm{min})$ was assessed. Since, the margin of safety with low dose $\mathrm{MgSO}_{4}$ therapy is very high, so low serum $\mathrm{MgSO}_{4}$ levels were not done. Intravenous labetalol was used as first line antihypertensive therapy, unless contraindicated, in patients who had systolic blood pressure $>160 \mathrm{mmHg}$ or diastolic blood pressure $>110$ $\mathrm{mmHg}$ to prevent cerebrovascular accidents.

Hydration was maintained by ringer lactate solution 1000 cc over 24 hours and intravenous fluids were restricted to prevent circulatory overload. Patients were encouraged to take fluids orally as soon as they recovered consciousness. Termination of pregnancy was undertaken in all cases of eclampsia. Delivery was expedited in the form of induction/augmentation of labor or LSCS depending upon assessment of each case.

\section{RESULTS}

Table 1 reflects the baseline characteristics like; age, residence, gravidity and booked unbooked status of patients. We observe that, the average of 114 included patients was $(25.6 \pm 3.84)$ years with majority of patients falling in the age group of (21-25) years, constituting about $(49.1 \%)$ followed by $(36.8 \%)$ patients falling in the age group of (26-30) years. Evidently, majority of patients were from rural background $(78.1 \%)$ and only $(21.9 \%)$ were from urban area. Majority of patients were primigravida accounting for $(71.1 \%)$ followed by women with multigravida status constituting about $(28.9 \%)$. The percentage of booked patients was $(40 \%)$ compared to $(59.6 \%)$ of unbooked patients.

Table 2 displays the distribution of associated complications and mortality rate. We observed that around (8\%) patients developed RTI complication followed by abruption placenta $(6.1 \%)$. Patients who had a temperature $>390^{\circ} \mathrm{C}$ were $(5.3 \%), \mathrm{PPH}$ and tongue bite complication was observed in $(4.4 \%)$ each. Rest of the less common complications were any of the following; CVA (1.8\%), coma $(0.9 \%)$, cerebal edema $(0.9 \%)$. Only 1 death was resulted in the given study.

We observe that the average hospital stay of patients was $(5.7 \pm 2.17)$ days, with majority of patients $(56.1 \%)$ had a hospital stay of 4-7 days. Only (7.9\%) patients had a hospital stay of $<4$ days and $(15.8 \%)$ patients had a hospital stay of $>15.8$ days.

Majority of the patients $(46.5 \%)$ had a gestational age of $>36$ weeks followed by $(18.4 \%)$ patients with gestational 
age ranging in the interval (32-36) weeks. Around (68.4\%) patients had either antepartum or intrapartum eclampsia and only $(31.6 \%)$ had postpartum eclampsia. The first fit was mostly observed at home, the percentage of first fit at home was $(58.8 \%)$ followed by $(29.8 \%)$ patients who had their first fit at other hospital. Only (11.4\%) patients had their first fit at LD hospital. Most of the patients constituting about $(54.4 \%)$ had SBP $(160-200 \mathrm{mmHg})$, $(37.7 \%)$ had SBP $<160 \mathrm{mmHg}$ and only $7.9 \%$ patients had their SBP > $200 \mathrm{mmHg}$. One hundred and five $(92.1 \%)$ patients had a convulsion $\leq 5$. Mode of delivery was analyzed among studied patients, we found that $(69.3 \%)$ patients had a spontaneous vaginal delivery, (5.3\%) had assisted vaginal delivery and (25.4\%) had LSCS.

Table 1: Baseline characteristics of study patients.

\begin{tabular}{|llll|}
\hline Variables & & $\mathbf{N}$ & $\%$ \\
& $<20$ & 6 & 5.3 \\
\cline { 2 - 4 } Age (years) & $21-25$ & 56 & 49.1 \\
& $26-30$ & 42 & 36.8 \\
\cline { 2 - 4 } & $31-35$ & 7 & 6.1 \\
\cline { 2 - 4 } Residence & $>35$ & 3 & 2.6 \\
\hline \multirow{2}{*}{ Gravidity } & Rural & 89 & 78.1 \\
\cline { 2 - 4 } & Urban & 25 & 21.9 \\
\hline \multirow{2}{*}{ Booked/unbooked } & Primigravida & 81 & 71.1 \\
\cline { 2 - 4 } & Multigravida & 33 & 28.9 \\
\cline { 2 - 4 } & Booked & 46 & 40.4 \\
\hline
\end{tabular}

Note: Mean \pm SD $($ range $)=25.6 \pm 3.84(18-37) ; n=114$.

Table 2: Maternal morbidity and mortality.

\begin{tabular}{|lll|}
\hline Complications & N & $\%$ \\
\hline RTI & 9 & 7.9 \\
\hline Abruptio placenta & 7 & 6.1 \\
\hline Pemperature $\mathbf{3 9 0}^{\circ} \mathbf{C}$ & 6 & 5.3 \\
\hline Tongue bite & 5 & 4.4 \\
\hline CVA & 5 & 4.4 \\
\hline Coma & 2 & 1.8 \\
\hline Cerebral edema & 1 & 0.9 \\
\hline Death & 1 & 0.9 \\
\hline
\end{tabular}

Table 3: Hospital stay (days) of study patients.

\begin{tabular}{|lll|}
\hline Hospital stay (days) & $\mathbf{N}$ & $\%$ \\
\hline $\mathbf{4}$ & 9 & 7.9 \\
\hline $\mathbf{4 - 7}$ & 64 & 56.1 \\
\hline $\mathbf{7 - 1 0}$ & 23 & 20.2 \\
\hline$>\mathbf{1 0}$ & 18 & 15.8 \\
\hline Total & 114 & 100 \\
\hline Mean $\mathbf{S D}=\mathbf{5 . 7} \pm \mathbf{2 . 1 7}(\mathbf{3 - 1 2}$ days) & & \\
\hline
\end{tabular}

\section{DISCUSSION}

In the present study on the management of eclampsia with low magnesium sulphate dosage, we analyzed several maternal outcomes. Out of 114 patients, none of the patients had a treatment failure.

However, only one patient had a fit recurrence on low dose magnesium sulphate and around $(99.12 \%)$ were managed successfully. Contemporarily to the literature; Nagar et al also reported a fit recurrence rate of $1.98 \% .{ }^{6}$ However, authors like Pritchard et al and Sibai et al have reported a treatment failure rate of $(1-2 \%)$ which is contrary to our results as no treatment failure was observed in the present study. ${ }^{7,8,10}$ In the present study, only one maternal death occurred due to stroke, it was a case of antepartum eclampsia. Maternal mortality on standard dosage of magnesium sulphate regimen have been reported to range from (0-21\%). Nagar et al in their study on the management of eclampsia with standard dosage of magnesium sulphate have reported a zero maternal mortality. ${ }^{6}$ However, Pritchard et al have reported a maternal mortality of $0.4 \%$ on standard dose of magnesium sulphate regimen. ${ }^{7}$ Likewise Seth et al and Sibai et al reported a maternal mortality on standard $\mathrm{MgSO}_{4}$ dosage management of eclampsia as $2 \%$ and $0.4 \%$ respectively. 8,9

We observe that around (8\%) patients developed RTI complication followed by abruption placenta (6.1\%). Patients who had a temperature $>390^{\circ} \mathrm{C}$ were $(5.3 \%), \mathrm{PPH}$ and tongue bite complication was observed in (4.4\%) each. Rest of the less common complications were any of the following; CVA (1.8\%), Coma (0.9\%), cerebal edema $(0.9 \%)$. Kumar et al reported in their study on low MGSO4 dosage management of eclampsia, that $(6.50 \%)$ patients developed respiratory tract Infection (RTI) and (4.87\%) patients developed $\mathrm{PPH}$ which is in consonance to our observation. ${ }^{10}$

In the recently held eclampsia trial by the eclampsia trial collaborative group (2), it was reported that approximately (1.8-3.1\%) patients developed pulmonary edema. Similarly, Seth et al reported in their study that $15.4 \%$ patients of eclampsia had PPH development, pulmonary edema and aspiration pneumonia was reportedly developed in $(3.8 \%)$ each. ${ }^{9}$ In the present study, we observed that the average hospital stay of patients was $(5.7 \pm 2.17)$ days, with majority of patients $(56.1 \%)$ had a hospital stay of 4-7 days. Only (7.9\%) patients had a hospital stay of $<4$ days and $(15.8 \%)$ patients had a hospital stay of $>15.8$ days. Likewise, Kumar et al reported that majority of the patients $(60.16 \%)$ had a hospital stay of less than 6 days which is similar to our observation. ${ }^{10}$ However, the average hospital stay reported by Regmi et al was 7.19 days which is different and above to what we observed in the present study. ${ }^{14}$

The present study revealed, very low fit recurrence rate, low mortality rate, zero treatment failure rate, no toxicity and $(99.12 \%)$ success rate. These findings have validated the previous studies due to authors like Sardesai et al and Seth et al. ${ }^{11,12}$ 


\section{CONCLUSION}

Apart from zero percent treatment failure rate, Low maternal mortality and fit recurrence rate encouraged us to continue the treatment with low dose $\mathrm{MgSO}_{4}$ regimen. Thus, low dose magnesium sulphate has been found very effective in treating the eclampsia and at the same time maintains the high safety margin.

\section{ACKNOWLEDGMENTS}

Words fail to express our indebtedness and gratitude to Dr. Adil Rashid and Dr Zahoor Ahmad for their constant undaunted support in Data analysis and other invaluable help, without their help, this task could not have been accomplished.

Funding: No funding sources

Conflict of interest: None declared

Ethical approval: The study was approved by the Institutional Ethics Committee

\section{REFERENCES}

1. Duley L. The global impact of pre-eclampsia and eclampsia. Semin Perinatol. 2009;33(3):130-7.

2. The Eclampsia Trial Collaborative Group. Which anticonvulsant for women with eclampsia? Evidence from the Collaborative Eclampsia Trial. Lancet. 1995;345(8963):1455-63.

3. Sibai BM. Magnesium sulfate is the ideal anticonvulsant in preeclampsia-eclampsia. Am J Obstet Gynecol. 1990;162(5):1141-5.

4. Pritchard JA, Cunningham FG, Pritchard SA. The Parkland Memorial Hospital protocol for treatment of eclampsia: evaluation of 245 cases. Am J Obstet Gynecol. 1984;148(7):951-63.
5. Roberts JM. Magnesium for preeclampsia and eclampsia. N Engl J Med. 1995;333(4):250-1.

6. Nagar S, Jain S, Kumari S. Reassessment of therapy of eclampsia: comparison of mortality and morbidity of mother and foetus with parenteral magnesium sulphate and lytic cocktail therapy. J Obstet Gynaecol India. 1988;38:250-5.

7. Pritchard JA, Cunningham FG, Pritchard SA. The Parkland Memorial Hospital protocol for treatment of eclampsia: evaluation of 245 cases. Am J Obstet Gynecol. 1984;148(7):951-63.

8. Sibai BM. Eclampsia. VI. Maternal-perinatal outcome in 254 consecutive cases. Am J Obstet Gynecol. 1990;163(3):1049-54.

9. Seth S, Nagrathi A, Singh DK. Comparison of low dose, single loading dose and standard Pritchard regimen of magnesium sulfate in antepartum eclampsia. Anatol J Obstet Gynecol. 2010;1:1-4.

10. Kumar S, Kumar S, Kumar D, Gupta A, Gupta S. Maternal Outcome in Eclampsia with Low Dose Magnesium Sulphate Therapy. JK Sci. 2017;17(4):196-9.

11. Regmi MC, Aggrawal A, Pradhan T, Rijal P, Subedi A, Uprety D. Loading dose versus standard regimen of magnesium sulphate in eclampsia--a randomized trial. Nepal Med Coll J. 2010;12(4):244-7.

12. Sardesai S, Maira S, Patil A. Low dose magnesium sulphate therapy for eclampsia and imminent eclampsiaregime tailored for Indian women. J Obstet Gynaecol India. 2003;56:546-50.

Cite this article as: Banotra $\mathrm{P}$. Low dose magnesium sulphate regimen and maternal outcome of patients with eclampsia. Int J Reprod Contracept Obstet Gynecol 2022;11:348-51. 